\title{
JOSÉ DE NEBRA, LA DEVOCIÓN Y LA SANTA CAPILLA DE LA VIRGEN DEL PILAR ${ }^{1}$
}

\author{
JOSÉ DE NEBRA, DEVOTION AND THE 'SANTA CAPILLA DE LA \\ VIRGEN DEL PILAR'
}

\author{
Luis Antonio González Marín \\ Departamento de Ciencias Históricas-Musicología, \\ IMF (CSIC), Barcelona
}

\section{Resumen:}

Las fuentes musicales autógrafas de José de Nebra, organista y vicemaestro de la Real Capilla de Madrid, y simultáneamente compositor para los teatros públicos, así como algunos hechos de su vida, ponen de manifiesto una personalidad extremadamente religiosa. De hecho, Nebra en cierta manera contribuye, a través de diversas acciones, a la construcción histórica de uno de los mayores símbolos religiosos hispánicos: el culto a la Virgen del Pilar.

Palabras clave:

José de Nebra, devoción, Misa, Salve, Zaragoza, El Pilar, Cuenca

\section{Abstract:}

Many autograph sources of the music composed by José de Nebra -organist and vice-master of the Royal Chapel, and simultaneously composer for the public theatres in Madrid-, as well as some facts of his life, reveal a highly religious personality. In fact Nebra -in some way and through various actions- contributes to the historical construction of one of the most notable Hispanic religious symbols: the cult devoted to the Virgin of El Pilar.

\section{Keywords:}

José de Nebra, religiosity, Mass, Salve Regina, Saragosse, El Pilar, Cuenca

1 Este trabajo se enmarca en las actividades realizadas con base en el Protocolo General y Convenio Específico de Colaboración firmados entre el CSIC y el Arzobispado de Zaragoza para realizar una investigación exhaustiva en el Archivo de Música de las Catedrales de Zaragoza. Agradezco a D. Isidoro Miguel, Canónigo Archivero-Bibliotecario del Cabildo de Zaragoza, las facilidades concedidas para realizar este y otros muchos estudios en los fondos capitulares zaragozanos. 
Desde muy joven José de Nebra (*Calatayud, Zaragoza, 1702; †Madrid, 1768) hace vida y carrera fuera de su Aragón natal. Ya antes de cumplir los diez años, en agosto de 1711, abandona con sus padres y hermanos la ciudad donde nació -Calatayud-y el Reino de Aragón para instalarse en Castilla, concretamente en Cuenca, donde el padre obtiene la plaza de organista de la catedral. A los quince años ya vive en Madrid y enseguida entra al servicio de la corte, que no abandonará hasta su muerte. Solo se ausentará de Madrid muy ocasionalmente, aparte, claro está, de su asistencia a las jornadas de la familia real a los reales sitios, en particular a Aranjuez. Las posibles y esporádicas salidas de Madrid registradas hasta ahora parecen tener que ver siempre con asuntos familiares, como la profesión de su sobrina Ignacia -hija de su hermano menor, Javier- como monja en el convento de San Lorenzo Justiniano de Cuenca -conocido como “Las Petras”- en 1747, o los fallecimientos de su padre y su madre, en diciembre de 1748 y junio de 1749 respectivamente, en la misma ciudad. No hay constancia de que regresara jamás a Calatayud ni de que conservara contacto con personas o instituciones de esta ciudad, pero sí es sabido que, aparte de las visitas que su hermano Joaquín, organista en Zaragoza, le dispensó en al menos un par de ocasiones, mantuvo ciertas relaciones con la capital aragonesa y con la ciudad del Júcar. ${ }^{2}$

A juzgar por algunas trazas que deja en sus autógrafos y por hechos documentados de su vida, Nebra pasa por ser hombre devoto. Como queda dicho en otros lugares, ${ }^{3}$ los encabezados y colofones de los manuscritos musicales que salen de su mano incluyen, casi sin excepción, jaculatorias y preces a santos y a diferentes advocaciones de la Virgen, a quienes el autor se encomienda o cuyo patrocinio solicita. Esto sucede tanto en fuentes que contienen música religiosa como en zarzuelas y piezas instrumentales. En algunas fuentes conservadas en el Archivo de Música de las Catedrales de Zaragoza encontramos expresiones del tenor siguiente: “Obertura con tromp.s Obues y V.s. J. M. y J. sean con migo Amen S.n Antonio y S.ta Matilde 1744”, "Sea a honor y Gloria de J. M. y J. q me asistan y am / paren ahora y siempre Amen”, "Zarzuela, donde ay Violencia, no ay culpa. hecha con el Amparo de María. Ss.ma del Pilar, J. M. y J. seanconmigo Amen / S.n Ant.o y S.ta Matilde", 5 "J. M. Y J. 1 Sinfonia de la 2 P.te Nra S.ra Del Carmen measista", "Sinfonia J. M. Y J. sean Conmigo amen. Nrâ S.ra del Milagro y S.n Anton[io]”, "J. M. Y J. sean Conmigo amen. Nra S.ra Del Pilar y S.n Antonio", 6 etc. No deja de sorprender que estos arranques píos se den en encabezados de composiciones teatrales de contenido que en la época pudo ser visto como algo escabroso -como, a ojos de los moralistas, lo era todo el teatro y cuanto tuviera relación con él, y no debemos olvidar a este respecto que Nebra pasó su vida en Madrid inmerso en el ambiente teatral- ${ }^{7} \mathrm{o}$ de piezas instrumentales para clave que en alguna ocasión traen

2 Saldoni, en una noticia de difícil verificación porque, como es habitual, no cita su fuente de información, sitúa a José de Nebra en Zaragoza al frente de una “orquesta, compuesta de cincuenta escogidas voces é instrumentos”, dirigiendo la ejecución de un oratorio compuesto por él mismo para celebrar la canonización de San Luis Gonzaga y San Estanislao de Kostka. Tal oratorio compuesto por José de Nebra, el organista de la Real Capilla residente en Madrid, existió y se estrenó, como mostraré en un trabajo de próxima publicación, pero hasta la fecha no he conseguido documentar la presencia del compositor en la capital del Ebro con ocasión del estreno. Cfr. SALDONI, 1881, Tomo IV, 2ª Sección (Catálogo): 37.

3 Cfr. GONZÁLEZ MARÍN, 2003: XVII; --, 2008b: 591-612; --, 2010: XI; --, 2011: 14-15.

4 Ambas en E-Zac, Fondo Nebra, sin signatura, Vendado Amor es, no ziego (1744), pp. 1 y 156, respectivamente comienzo y final del manuscrito autógrafo.

5 E-Zac, Fondo Nebra, sin signatura, Donde hay violencia no hay culpa (1744), f. 1r.

6 Las tres en E-Zac, Fondo Nebra, sin signatura, Manuscrito autógrafo de tecla, ff. 2r, 32r y 33v respectivamente.

7 José de Nebra, aparte de su dedicación al la música escénica o quizá justamente por eso mismo, tenía su casa en la plazuela del Ángel, a pocos pasos de los teatros de la Cruz y del Príncipe, de modo que literalmente vivía rodeado de actores, actrices, cantantes, etc. Sobre las diatribas morales en contra del teatro, aún en el siglo XVIII, cfr. el clásico estudio de COTARELO, 1904. 
títulos, como sucede en ciertas tipologías de la música francesa, que habrían provocado las iras de algunos predicadores, como, por ejemplo, La inconstancia de amor, título de un minué que forma parte de un orden de piezas de tecla compuesto, según el autor indica, bajo el amparo de la Virgen del Pilar y San Antonio. Pero, lógicamente, ejemplos similares se hallan en muchos autógrafos que contienen producción litúrgica de Nebra conservada en el Archivo General de Palacio. ${ }^{8}$ El hecho de encabezar un manuscrito cualquiera -una carta, un texto, una composición musical- con una alusión religiosa en señal de piedad y solicitud de protección -por ejemplo, dos pequeños trazos que se cortan perpendicularmente formando una cruz- es más que común en aquel tiempo, y quizá tiene más de fórmula que de otra cosa. Lo mismo sucede con la invocación a la Sagrada Familia -“J[esús], M[aría] y J[osé]”-, que, como José de Nebra, también usan regularmente otros miembros de la familia y gente próxima, como su hermano Joaquín, organista en La Seo de Zaragoza, o Pedro Aranaz, que fue infante en esta ciudad, donde muy posiblemente trató al organista Joaquín Nebra. ${ }^{9}$

Algunas de estas jaculatorias parecen evocar hermandades y cofradías con las que Nebra pudo tener alguna clase de proximidad, así como devociones particulares a determinadas imágenes concretas tenidas por milagrosas. Para otras deben buscarse explicaciones de diverso tipo.

La encomienda más habitual, casi invariable, de José de Nebra se dirige a "Jesús, María y José, San Antonio y Santa Matilde". Si las devociones por la Sagrada Familia y por San Antonio quizá no requerirían de mayor explicación, ${ }^{10}$ sí caben algunas notas sobre Santa Matilde. No he podido constatar la existencia de un particular culto a esta santa en ninguna de las ciudades en que residió Nebra (Calatayud, Cuenca, Madrid), pero es sabido que el compositor bilbilitano puso música a una comedia de santos de José de Cañizares titulada Música discreta y santa, Santa Matilde, que con la loa, sus tres jornadas, los entremeses y el correspondiente fin de fiesta se estrenó en el madrileño teatro -aún corral, entonces- de la Cruz el día de Navidad de 1729, por la compañía de Manuel de San Miguel. ${ }^{11}$ Esta Santa Matilde -que seguramente es la abogada a la que acude Nebra- no es Matilde de Ringelheim (†968), reina esposa de Enrique I el Pajarero, cuya fiesta se celebra cada 14 de marzo, sino la también germana Mechthild von Hackeborn (†1298), mística

8 Véanse algunos ejemplos en mis mencionadas ediciones del Oficio y misa de difuntos, Miserere a 8 e Himno de Santa Isabel, Reina de Portugal. Algunos más se citan en PERIS LACASA, 1993, o en SANDOVAL DÍEZ, 2011.

9 He registrado la jaculatoria "J. M. J. sean Conmigo" en algunas obras del tudelano Pedro Aranaz y Vides (1740-1820) conservadas en Zaragoza y Cuenca, que de ningún modo se pueden confundir con los autógrafos de Nebra, pues la caligrafía es muy diferente. Pero no deja de llamar la atención que el uso de tal jaculatoria, común por lo demás, sea compartido por los Nebra -al menos José y Joaquín- y Aranaz, que se educó en Zaragoza - como infante en El Pilar, aunque probablemente también trató a Joaquín Nebra- y desde 1769 trabajó en Cuenca, donde copió algunas obras de José de Nebra. Aranaz mantuvo algún vínculo posterior con El Pilar de Zaragoza, como se verá.

10 Por San Antonio solemos entender San Antonio de Padua, y no San Antonio Abad, comúnmente conocido en España como San Antón. La devoción al franciscano portugués estaba muy extendida en todo el ámbito hispánico desde el siglo XVII, y en Madrid sus devotos respondían al apodo de "guinderos", por asociarse la fiesta del santo (13 de junio) con la época de recogida y consumo de cerezas. En 1720 se fundó una Real Congregación de San Antonio "el guindero", con sede en la iglesia de la Santa Cruz, en la calle de Atocha, próxima a la Plaza Mayor, y para ella se edificó una ermita diseñada por José Benito de Churriguera, que en 1768 sería demolida y reconstruida por Sabatini en diferente emplazamiento, antes de la edificación por Filippo Fontana de la ermita de San Antonio de la Florida, la que decoraría Goya. Cfr. BUENDÍA MUÑOZ, 1992. Por cierto, José de Cañizares, libretista colaborador de Nebra hasta su muerte en 1750, escribió una comedia sobre la devoción al santo casamentero: Lo que vale ser devoto de San Antonio de Padua.

11 Cfr. PÉREZ PASTOR, 1910: 87-88, y KLEINERTZ, 2003, vol. II: 205. Cañizares cobró 1.500 reales de vellón por el libreto, mientras que Nebra sólo percibió 600 por la música. 
cisterciense que se festeja el 19 de noviembre, de cuya vida da noticia el Liber specialis gratiae, atribuido a su pariente Gertrudis. ${ }^{12}$ La tradición hace a esta Santa Matilde cantora -se la llama "el ruiseñor de Dios" y de ella se predica que tuvo una "voz de una suavidad maravillosa"- y maestra del coro del monasterio de Helfta. ${ }^{13}$ Puede que estas habilidades musicales de Matilde indujeran a Nebra a incluirla en su santoral particular.

Invoca Nebra en alguna de sus jaculatorias al Santísimo Sacramento del altar. No es preciso extenderse sobre la importancia que las fiestas eucarísticas tienen en la Edad Moderna, desde el Corpus -para cuyas celebraciones Nebra pone música a más de una veintena de autos sacramentales desde 1723 en adelante- ${ }^{14}$ a las Cuarenta Horas, pasando por las misas y actos promovidos por las llamadas "cofradías de la Minerva". ${ }^{15}$ De hecho, la parroquia de San Sebastián de Madrid, de la que era vecino y parroquiano José de Nebra -que vivía en la plazuela del Ángel y se hizo enterrar en la citada igesia-, ofrecía su sede en el siglo XVIII a una hermandad sacramental, con la que tal Nebra tuvo algún contacto. ${ }^{16}$ También se pone bajo la protección del Santísimo Cristo del Consuelo, ${ }^{17}$ advocación común en hermandades y cofradías e incluso en fiestas patronales, ${ }^{18}$ pero en este caso quizá pueda vincularse con una devoción particular de la ciudad natal de Nebra: en efecto, en la iglesia mudéjar de San Andrés de Calatayud existe un Santo Cristo del Consuelo, una históricamente muy reverenciada talla anónima del siglo XVI.

Nebra recurre a varias advocaciones marianas: María Santísima del Milagro, ${ }^{19}$ la Virgen del Carmen $^{20}$ y Nuestra Señora de la Humildad. ${ }^{21}$ Seguramente la primera de ellas debe identificarse con una

12 Existe una edición del Liber specialis gratiae realizada por Louis Paquelin y publicada por la Abadía de Solesmes (Poitiers-París) en 1877. En GALLICA puede consultarse una copia de mediados del siglo XV que conserva la Biblioteca Nacional de Francia (http://gallica.bnf.fr/ark:/12148/btv1b9080960w/f3.image.r=.langES). Cisneros promovió que se publicase una traducción del Libro de la gracia espiritual (Toledo, 1510), que, al parecer, causó vivo interés en Santa Teresa de Ávila y otros místicos españoles del siglo de oro. Cfr. BARAUT, 1965: 27, nota 65. Nótese también que, antes de la composición de Música discreta y santa, Santa Matilde, José de Cañizares ya había dedicado una comedia (en dos partes, ambas de 1701) a La más amada de Christo, Santa Gertrudis la Magna, así como una Introducción en forma de baile para la comedia de Santa Gertrudis, en 1716, cuyo manuscrito conserva la Biblioteca Nacional de Madrid. También en las Américas hubo comedias dedicadas a las santas de Helfta; cfr. ARELLANO y EICHMANN, 2005.

13 Cfr. FINNEGAN, 1991: 26-28.

14 Cfr. GONZÁLEZ MARÍN, 2008a: 16-19.

15 Desde el siglo XIII hay constancia de celebración de procesiones para el Corpus Christi, y las cofradías eucarísticas se fueron multiplicando a raíz de algunas fundaciones romanas, como la del viático en San Lorenzo in Damaso (1501) o la de la iglesia de Santa Maria sopra Minerva (1539). Al parecer la impulsora de la instauración de este tipo de cofradías sacramentales en España fue Teresa Enríquez, apodada "la loca del Sacramento", que obtuvo para ello bula de Julio II. El culto sacramental, en variadas formas de religiosidad de gran arraigo (procesiones, cofradías "de la Minerva”, representación de autos sacramentales...), creció a lo largo del siglo XVII y se mantuvo en el XVIII, aun después de la prohibición de los autos sacramentales en 1765.

16 Información abundante sobre esta parroquia, el vecindario y sus actividades se encontrará en FERNÁNDEZ GARCÍA, 1995.

17 Sucede esto en la fuente autógrafa del Miserere a 8 (1750), conservada en el Archivo General de Palacio, signatura Leg. 1557, no 897: "J. M. Y J. sean conmigo Amen S.n An.to y S-ta Matilde / Miserere a 8 con V.s trompas Obues y flau / tas. escrito con el particular patrocinio / de el SS.mo Christo de el con suelo, y su / Sacratísima Madre, S.ta M.ía". Cfr. GONZÁLEZ MARÍN, 2010: XI.

18 Por ejemplo, en Clares y en Villarroya de la Sierra, en la comarca de Calatayud, donde se celebra esta fiesta, con su romería, hacia finales de agosto y finales de septiembre, respectivamente.

19 Por ejemplo, en la fuente autógrafa de la Misa in sono tubae de 1748 (N.17/ Missa A 8. / In sono tube / Con VV.s Oboes, Tromp.s y Viola / D.n Josef Nebra / Año 1748. / escrita con el particular patrocinio de mi M.e y S.ra M.a SS.ma del Milagro / Dedicada / A la Catholica Mag.d del Rey / nrô. Señor. / D. Fernando el Sexto); Madrid, Archivo General de Palacio, Leg. 1.546. Cat. 871; o en la Misa Jubilate in conspectu Regis Domini, de 1751 (N. 19 / Mui Larga / Jubilate in Conspectu Regis Domini / Missa a 8 / Oboes, Trompas y Clarines / 1751 / Joseph Nebra / escrita con / el particular patrocinio de / Mi Madre y S.ra Maria / SS.ma de el Milagro); Madrid, Archivo General de Palacio, Leg. 1.549. Cat. 878.

20 E-Zac, Fondo Nebra, sin signatura, Manuscrito autógrafo de tecla, f. 2r.

21 Por ejemplo, en la Misa canticum novum (No. 18 / Missa A 8. / Canticum novum. / con VV.s Oboes, y Viola / Josef Nebra 
imagen concreta, esto es, con la pintura conservada y venerada en la Capilla del Milagro del convento de las Descalzas Reales, en el cual Nebra trabajó como organista en su juventud y que, por tanto, conocería bien. Esta capilla había sido dotada por el segundo Don Juan de Austria con motivo de la profesión en las Descalzas de su su hija natural sor Margarita de la Cruz en 1666. La célebre tabla de Nuestra Señora del Milagro suele atribuirse al emiliano Paolo de San Leocadio, activo en Valencia entre 1472 y 1520 y posible autor también de las pinturas murales descubiertas en el presbiterio de la catedral de Valencia. Esta tabla tiene fama de milagrosa desde el siglo XVI, y en su entorno se han practicado desde antiguo devociones que presentan algún parentesco con las de la Virgen del Pilar de Zaragoza. ${ }^{22}$

La Virgen del Carmen es una advocación más común y extendida; famosa y muy venerada era en Madrid la escultura de Juan Sánchez Barba (ca. 1656-1657) ${ }^{23}$ que hoy se puede contemplar en la actual iglesia de Nuestra Señora del Carmen y San Luis Obispo, antes iglesia del convento del Carmen Calzado, sita en la calle del Carmen junto a la Puerta del Sol. En cuanto a Nuestra Señora de la Humildad, en Madrid existía una hermandad de este nombre que a mediados del siglo XVIII se hallaba establecida en el oratorio de los Padres Misioneros del Salvador del Mundo, como atestigua la publicación de sus constituciones. ${ }^{24}$

Seguramente por ser oriundo del Reino de Aragón y por el vínculo familar existente con Zaragoza, donde sus dos hermanos varones menores trabajaron como organistas sucesivamente, ${ }^{25}$ José de Nebra efectúa ciertas demostraciones de fervor pilarista, ${ }^{26}$ alguna de las cuales excede en mucho lo que sería habitual en un particular. Por ahora he localizado la encomienda a la Virgen del Pilar en varios encabezados de fuentes musicales autógrafas, como dos ya citadas, presentes en la compilación de música de tecla conservada en Zaragoza, no fechada (“J. M. Y J. sean Conmigo amen. Nra S.ra Del Pilar y S.n Antonio"), ${ }^{27}$ y en la zarzuela Donde hay violencia no hay culpa, de 1744 (“[,.,] hecha con el Amparo de María. Ss.ma del Pilar [...]"), ${ }^{28}$ o las que se hallan en tres misas fechadas en 1748 y conservadas en el Archivo General de Palacio: la Misa In viam pacis (N.o 2. / Missa a 8. / Con VV.s y Viola. / In viam Pacis. / Josef Nebra. / Año de 1748 / escrita con el singular patrocinio/ de mi M.e y S.a Maria / ss.ma del Pilar / Dedicada /

/ Año 1748 / escrita con el particular auxilio de N.ra S.ra de la / Humildad / Dedicada / A la Catholica Magd del Rey / nrô. Señor / D. Fernando el Sexto); Madrid, Archivo General de Palacio, Leg. 1.544. Cat. 864.

22 Sobre la historia y devociones de la Virgen del Milagro, cfr. EBAS, 1712, donde, aparte de presunciones sobre el origen de la imagen, se explica el desarrollo de la fiesta y novenario (del 3 al 11 de julio), con amplia presencia musical -en la que Nebra habría de participar durante sus años como organista en las Descalzas, bajo el magisterio de José de San Juan- y se detalla incluso la venta de cintas con la medida de la Virgen, como sucede aún hoy en El Pilar de Zaragoza. Valga como hecho anecdótico que José de Nebra moriría precisamente el último día del novenario de Nuestra Señora del Milagro (el 11 de julio, festividad de las Nieves) del año 1768. Cfr. también DELCLAUX y SANABRIA, 1991: 95-97.

23 Cfr. BLANCO MOZO, 2005.

24 Constituciones de la Hermandad de Nuestra Señora de la Humildad: sita en la iglesia oratorio de Padres Misioneros del Salvador del Mundo [...], Madrid, Joachin Ibarra, MDCCLIX [1759], cit. en AGUILAR PIÑAL, 2002: 178. La Hermandad de Nuestra Señora de la Humildad existía ya en el siglo XVII.

25 Javier Nebra fue organista en La Seo de Zaragoza entre 1727 y 1729, en que pasó a Cuenca; lo sucedió en la tribuna zaragozana su hermano Joaquín, que la ocupó desde 1730 hasta su muerte en 1782. Cfr. EZQUERRO ESTEBAN, $2002: 117$.

26 No es preciso introducir aquí una síntesis de la devoción a la Virgen del Pilar como fenómeno histórico. La literatura al respecto es amplísima. Remito para cualquier consulta a las obras de referencia de ARMILLAS VICENTE et al., 1984 y BUESA CONDE, 1995.

27 E-Zac, Fondo Nebra, sin signatura, Manuscrito autógrafo de tecla, f. 33v.

28 E-Zac, Fondo Nebra, sin signatura, Donde hay violencia no hay culpa (1744), f. 1r. 
A la Cathólica Magestad del / Rey Nro Señor. D. Fernando el VI), ${ }^{29}$ la Misa Laudate Dominum de terra (No. 16 / Missa A 8. con bajo en 1.a choro / Laudate Dominum de terra / Con VV.s oboes y trompas. / D.n Josef Nebra / Año 1748 / escrita con la particular protecc.n / de mi M.e y S.a Maria Ss.ma del Pilar / Dedicada / A la Catholica Magestad del Rey / nrô Señor / D. Fernando el Sexto) ${ }^{30}$ y la Misa Laudate nomen Domini (N. ${ }^{\circ} 1$ / Missa A 8. / Con VV.s oboes y Viola / Laudate nomen Domini / Josef Nebra / año 1748 / Misa ligera escrita con el particular Patrocinio de J. M. J y Sta. / Maria Ss.ma De el Pilar). ${ }^{31}$ Pero, aparte de estas invocaciones escritas, que muy pocas personas podrían leer en su día -salvo los copistas encargados de extraer las partichelas y tal vez, ocasionalmente, el cardenal Mendoza, Patriarca de las Indias Occidentales y jerarca máximo de la Real Capilla, con quien el piadoso José de Nebra supo manejarse siempre en los mejores términos-, en sus últimos años de vida tuvo Nebra la oportunidad de hacer pública demostración de devoción pilarista a través de dos acciones, con destino a Zaragoza y Cuenca, y en dos facetas distintas: la de compositor y la de mecenas. Además, ambas acciones ponen de manifiesto la proximidad de Nebra con otros relevantes artistas de la corte y tal vez con cierto lobby aragonés que, desde mediados del siglo XVIII, se hace notar en Madrid.

Dentro de la larga y compleja historia del templo de El Pilar de Zaragoza, la Santa y Angélica Capilla, que da cobijo a la columna que la tradición hace traída por ángeles a orillas del Ebro ante al apóstol Santiago y con presencia de la Virgen, aún en vida, fue durante siglos un edículo anexo a la iglesia hasta que varios proyectos del siglo XVII firmados por Felipe Busiñac, Felipe Sánchez y Francisco Herrera el Mozo, cuyas obras se iniciaron en 1681, se propusieron incorporarla dentro de un templo de mayores dimensiones. Los trabajos se demoraron y, al fin, el proyecto de restructurar y ornamentar la Santa Capilla para albergar la columna, ya en el interior de la nueva iglesia, cayó en 1750 en manos de Ventura Rodríguez, arquitecto de la corte de Fernando VI, el cual dio su beneplácito al proyecto un año después. En el equipo de artistas involucrados encontramos entre otros al escultor aragonés José Ramírez de Arellano y al pintor madrileño Antonio González Velázquez. Las obras, complicadas por cuestiones de orientación y cimentación y por la necesidad de no mover la columna, que según la tradición habría de permanecer inmóvil hasta el fin de los tiempos, se prolongaron varios años y el nuevo templete, totalmente ornamentado y acabado, se inauguró solemnemente durante las fiestas del Pilar de $1765 .{ }^{32} \mathrm{El}$ abogado y literato zaragozano Manuel Vicente Aramburu de la Cruz ( $\dagger 1768$ ) narra por extenso la peripecia histórica de las obras y las fiestas de 1765 en su Historia cronológica de la Santa Capilla de la Virgen del Pilar de Zaragoza, publicada en 1766. Además de la descripción pormenorizada de cada elemento artístico de la nueva Santa Capilla, Aramburu da noticia de la presencia musical en las celebraciones que tienen lugar en la ciudad desde días antes del 12 de octubre de 1765 hasta cumplida la octava. Describe así una Misa en un “Theatro” erigido en la Universidad, a la que asistió el Ayunta-

29 Madrid, Archivo General de Palacio, Leg. 1.544. Cat. 862.

30 Madrid, Archivo General de Palacio, Leg. 1.547. Cat. 874.

31 Madrid, Archivo General de Palacio, Leg. 1.543. Cat. 861.

32 La bibliografía sobre la Santa Capilla, su idea y diseño y su proceso de realización es amplísima, pero destacaré ANSÓN NAVARRO, 2006; ESTEBAN LORENTE, 1987 y 2006; RINCÓN GARCÍA, 2000; USÓN GARCÍA, 1990; y DOMINGO PÉREZ, ANSÓN NAVARRO y RUIZ PARDO, 1998. 
miento precedido por clarines y timbales: "la Música de los dos Santos Templos con tantos Violines, Trompas, Clarines, Trompetas, Favotes, y otros Instrumentos, y entonando una Missa de tan armoniosa composición, que suspendió lisonjeramente al oìdo, haciendo partícipe de su deliciosa ocupación al entendimiento por el grande estudio con que brillaba en estilo, passos, intentos, y suabidades". ${ }^{33}$ Poco más allá indica que "sonò otra vez el concierto de Música". ${ }^{34}$

Desde la página 375 Aramburu alude a la música de la fiesta mayor del 12 de octubre, con la correspondiente misa pontifical, y es aquí donde encontramos a José de Nebra:

El Cabildo con su Clero, y las Capillas de las dos Iglesias, à que se aumentaban otros Músicos de singular ha- [p. 376] bilidad, que sonaban Trompas, Clarines, Tymbales, Fabotes, Obuès, y Flautas, y otros no vulgares Instrumentos, para que con nunca oìda delicadeza llegasse el arte à la última línea de la harmonìa, estaba cantando en el Choro las Horas, y à poco rato, que esperaba el Ayuntamiento, llegò acompañado de su Guión, y de muchos Señores Prebendados, que salieron à recibirle à la puerta, según se acostumbra, el Ilustrísimo Señor Don Luis García Mañero, nuestro amado Arzobispo [...]. Revestido su Ilustrísima, se empezó à cantar la Missa, de Composición de Don Joseph Nebra, Organista Primero, y Vice-Maestro de la Capilla Real, y Maestro de Música del Sereníssimo Señor Infante Don Gabriel, que como tan ferviente apassionado de Nuestra Imagen Soberana, como yà dixe en el Capítulo X, la remitiò desde Madrid [p. 377] con una Salve, para que se cantassen en su santo día: En ellas sobresalìan todos los primores del Arte, en el Estudio, en el Estilo, y en la Harmonìa, con tan acertado primor, que à los Professores los instruían, y à los que no lo somos nos suspendían, y admiraban. ${ }^{35}$

Así pues, según el relato de Aramburu, José de Nebra habría enviado desde Madrid, sin desplazarse a Zaragoza, dos composiciones: una Misa para la pontifical de bendición de la nueva Capilla Angélica, y una Salve, que quizá se cantaría tras la misa o por la tarde, siempre en la Santa Capilla. La búsqueda de información relativa a tal envío en los fondos documentales de los Archivos y Biblioteca Capitulares de Zaragoza se ha revelado, hasta el momento, infructuosa. Sin embargo, el fondo de obras de José de Nebra conservado en el Archivo de Música de las Catedrales de Zaragoza, que ordinariamente relacionamos con una parte del legado del músico a su único hermano superviviente, Joaquín, puede ofrecer alguna pista. Este archivo conserva copias, no datadas pero indudablemente contemporáneas a Nebra -como se desprende de los rasgos caligráficos de los copistas, que podemos identificar con algunos de los que, en el entorno de la Real Capilla de Madrid, trabajaron para el compositor-, de dos de las misas en cuyos autógrafos hoy conservados en Madrid Nebra indica que fueron compuestas en 1748 bajo el patrocinio de la Virgen del Pilar: la Misa In viam pacis, cuya fuente zaragozana trae el título de Misa â 8 con Violinos. oboes y Viola In viam pacis Del S.r D.n Joseph de Nebra, y la Misa Laudate Dominum de terra, que en su fuente zaragozana se denomina de la Misa Grande de D.n Joseph Nevra. Hoy conocemos cerca de treinta misas atribuidas a José de Nebra, dispersas en archivos españoles y mexicanos y fechadas entre 1731 y

33 ARAMBURU DE LA CRUZ, 1766: 346.

34 Ibid:: 348 .

35 Ibid:: 375-377. 
1766. Puede pensarse que, para una ocasión especial como la que se presentaba, Nebra debería haber compuesto una obra nueva, pero bien pudo recurrir a una composición preexistente, sobre todo si ésta no era conocida en Zaragoza. Me inclino, pues, a pensar que cualquiera de esas dos misas relacionadas de algún modo con la devoción pilarista pudo ser la que solemnizó la misa pontifical del 12 de octubre de 1765 en El Pilar, aunque el hecho de que hoy sólo existan en Zaragoza las partituras generales y no los correspondientes juegos de partichelas podría operar en contra de tal suposición; en todo caso, si cabe que la ausencia actual de partichelas sea síntoma de que esas obras no llegaron a ejecutarse en Zaragoza, también es razonable pensar que se trata únicamente de un problema de conservación, como tantas veces sucede, o incluso de que el autor reclamara -y consiguiera- la devolución de los materiales después de su uso, dejando a cambio una partitura para el archivo. Por otro lado, el fondo zaragozano posee copia en partitura de otra misa de Nebra, la Misa Pange lingua de 1747 (Misa á 8. con Violin.s Clarin, y Viola, sobre el Pangelingua de D.n Joseph Nebra), y un estudio exhaustivo de los abundantes fondos anónimos del siglo XVIII del citado archivo tal vez depare sorpresas en el futuro.

En cuanto a la Salve, el Archivo de Música de las Catedrales de Zaragoza no conserva ninguna fuente atribuida a Nebra con esta tipología de composición, pero he localizado una Salve anónima que se corresponde totalmente con los parámetros estructurales y estilísticos de composiciones similares debidas a Nebra, preservadas en manuscritos autógrafos en el Archivo General de Palacio, así como con los rasgos caligráficos de alguno de los copistas habituales de Nebra. ${ }^{36} \mathrm{La}$ Salve a la que me refiero ${ }^{37}$ es una obra a dos coros (con la disposición a 9 SSAT / SSATB, aunque en realidad a menudo se trata de un coro duplicado) con dos oboes, dos trompas (ocasionalmente clarines, probablemente ejecutados por el mismo par de instrumentistas), dos partes de violín y bajo, estructurada en seis números de la manera siguiente: ${ }^{38}$

1. Salve Regina $2 \# \operatorname{Sim} 3 / 4$ $\mathrm{ob} 1, \mathrm{ob} 2, \operatorname{tr} 1, \operatorname{tr} 2, \mathrm{v} 1, \mathrm{v} 2$, coro I SSAT, coro II SSATB, acompto. Indicaciones de Lento y Largo

2. Ad te clamamos $2 \# \operatorname{ReM} 2 / 4$ ob1, ob2, cl1, cl2, v1, v2, coro I SSAT, coro II SSATB, acompto.

Sin indicación

3. Ad te suspiramos $2 \mathrm{~b}$ SibM $3 / 4$

S o T (escrito en Do en $1^{\text {a }}$ línea, aunque indica "Solo Tenor"), ob1, ob2, v1, v2, acompto. Indicación de Larcheto Cantabile

4. Eia ergo 1\# SolM

$\mathrm{S} 1, \mathrm{~S} 2, \mathrm{ob} 1, \mathrm{ob} 2, \operatorname{tr} 1, \mathrm{tr} 2, \mathrm{v} 1, \mathrm{v} 2$, acompto.

Indicación de Allegro Gracioso

36 Aunque ya existen algunos trabajos que citan los copistas de la Real Capilla en relación con Nebra, como SANDOVAL DÍEZ, 2011, la Tesis Doctoral de Celestino Yáñez Navarro sobre los fondos de Scarlatti conservados en Zaragoza, en proceso, aportará nuevos datos de interés al respecto.

37 E-Zac D-6/34.

38 Especifico incipit de texto, armadura, tono, compás, plantilla vocal e instrumental: ob=oboe, tr=trompa, cl=clarín, v=violín, acompto.=acompañamiento) e indicación de tempo o carácter. 


\section{Et Jesum $1 \# \operatorname{Mim} \varnothing$}

ob1, ob2, tr1, tr2, v1, v2, coro I SSAT, coro II SSATB, acompto.

Sin indicación [fugato alla breve]

6. O Clemens $2 \# \operatorname{Sim} 3 / 4$

ob1, ob2, clarín1, cl2, v1, v2, coro I SSAT, coro II SSATB, acompto.

Indicación de Largo

He podido examinar una quincena de salves atribuidas a Nebra, algunas de ellas en fuentes autógrafas del Archivo General de Palacio, fechadas entre los años 1752 y 1767. Entre éstas hay alguna compuesta ad longum, varias en tres números y una, fechada en 1753, que coincide en tonalidad y planteamiento general de la composición, en seis números (Andantino, Allegro assai, Andante grazioso, Allegro, Allegro Vivo, Andante), con la que nos ocupa, aunque no se trata de la misma obra ${ }^{39}$ Dicho sea con todas las precauciones y riesgos que las atribuciones por análisis formalista de estilemas conllevan, la pieza anónima de Zaragoza parece corresponderse con el estilo del Nebra maduro que encontramos en el Oficio y misa de difuntos de 1758 o en el Miserere a dúo, no fechado, que conserva el mismo archivo en dos copias. ${ }^{40}$

La entusiasta relación de Aramburu habla también de otras muchas manifestaciones musicales en aquellos días, como misas, oratorios y salves del maestro de capilla de El Pilar Bernardo Miralles, del de La Seo Francisco Javier García Fajer, de Pedro Aranaz y de Gregorio Fondeira, que se prolongaron varias jornadas hasta cumplir el octavario, el 19 de octubre. Pero la colaboración de Nebra con la música de las fiestas pilaristas de 1765 termina aquí.

Sin embargo, José de Nebra protagoniza por aquellos mismos años otra acción devota con la Virgen del Pilar por medio, esta vez en Cuenca, donde su familia -con él mismo siendo niño- se había establecido en 1711. Muy próximo a la catedral, en la que trabajaron su padre y su hermano Javier, el convento de San Lorenzo Justiniano o de "las Petras" acogió a tres miembros femeninos de la familia: su hermana Mariana, su cuñada Juana -viuda de su hermano Javier, muerto prematuramente a los treinta y seis añosy su sobrina Ignacia -hija de éstos-, aunque sólo Mariana e Ignacia fueron monjas profesas. Asimismo, la iglesia de las Petras fue elegida como lugar de enterramiento de la familia: en ella fueron sepultados, según habían dejado escrito en su testamento otorgado en 1747, José de Nebra padre y su esposa Rosa Blasco, "en una sepultura que está al pie del altar de Nuestra Señora del Pilar". ${ }^{11}$ Un Libro de Visita de este convento que comprende los años 1729-1771 aporta algunos datos sobre la hermana y sobrina monjas: ${ }^{42}$ Mariana de Nebra figura en la documentación del convento ocupando diferentes cargos desde 1729 hasta

39 Madrid, Archivo General de Palacio, leg. 1559 cat. 921: Salve a 8 con Versos solos de / Tiple y Contralto. con / oboes, trompas y Flautas / y Clarines / 1753.

40 Próximamente ofreceré un análisis detallado de esta composición y una edición de la misma, dentro de un proyecto de reconstrucción de la música para las fiestas inaugurales de la Santa Capilla del Pilar (1765), con motivo de su tricentenario (2015).

41 Libro de Entierros de la Parroquia de San Nicolás de Cuenca, ff. 39v-40r, cit. en ÁLVAREZ MARTíNEZ, $1993: 197$.

42 La escasa documentación del siglo XVIII superviviente en el convento de San Lorenzo Justiniano de Cuenca (el +1 LIBRO DE VISI / TA, Y ELECZION / DE ABADESA Y OFI / CIALAS QVE SE = / HAZEN POR LOS / VISITADORES DE / S. PEDRO / DE CVUEN= / CA) ha Sido puesta amablemente a mi disposición por la Madre Eulalia, a quien expreso mi agradecimiento, que hago extensivo a su capellán, D. Manuel Martínez Moset y a D. Antonio Chacón, Canónigo Archivero de la Catedral de Cuenca. 
al menos 1747: Refitolera. Sub-vicaria, Ropera, Secretaria, Vicaria de Coro, Enfermera, Portera de Torno, Sacristana y Provisora. ${ }^{43}$ Seguramente murió antes de 1750 , pues ya no la encontramos en la relación de cargos de ese año, donde sí comparece Ignacia de Nebra, que hereda algunos de los puestos que antes ocupó su tía y cubre algunos nuevos: Ropera, Refitolera, Sacristana, Vicaria de Coro, Portera, Maestra de Novicias, Secretaria, Tornera y Diputada. ${ }^{44}$ Es de notar que en la entrada correspondiente al año 1765 -fecha significativa- Ignacia de Nebra cambia su nombre por el de Ignacia de Nuestra Señora del Pilar.

El citado cronista zaragozano Aramburu de la Cruz es quien llama la atención sobre la obra emprendida por José de Nebra en el convento de las Petras. Tratando en su Historia cronológica de la Santa Capilla de algunas otras capillas dedicadas a la Virgen del Pilar en diversos lugares de España, escribe Aramburu:

En la Ciudad de Cuenca es Titular de un Templo, que ha edificado à sus expensas Don Joseph Nebra, Organista, y Vice-Maestro de la Capilla Real, y Maestro de Música del Señor Infante Don Gabriel, en el Convento de Religiosas de S. Lorenzo Justiniano, en que ha instituìdo una Hermandad, que se compone de muchos Prebendados de su Santa Iglesia, y de Sugetos de la primera distinción, la que celebra su fiesta con grande aparato, exponiendo à la adoración con aprobación del ordinario en un precioso relicario de plata un fragmento de la Sagrada Columna, que pudo conseguir su fervoroso Fundador, en premio de su devoción, con authéntica del Señor Vicario General, Capitular de esta Santa Iglesia. ${ }^{45}$

Pocos años más tarde, en 1774, Antonio Ponz ratifica esta información y aporta algunos datos más en su Viage de España:

A la plazuela de la catedral corresponde la puerta de la Iglesia de S. Pedro, que es de Monjas de S. Lorenzo [p. 117] Justiniano: su figura es elíptica, y parecida en su planta á la de las Monjas Bernardas de Alcalá, [p. 104] que ya he referido á V. desde aquella Ciudad. Esta de Cuenca es obra pocos años hace renovada, ó por mejor decir fabricada del todo; porque de lo antiguo nada se ve en ella. Me aseguran que la costeó D. Diego Emo, Canónigo de esta Catedral, y D. Joseph Nebra, célebre Maestro de Capilla, y Organista, que murió al servicio de S. M. no há muchos años, dexando memoria de su habilidad. La arquitectura fue ideada por D. Alexandro Velázquez, según me han dicho, Individuo que fue de esa Real Academia de S. Fernando, á quien V. habrá conocido, y sabrá su práctica, é inteligencia en pintar arquitectura, y ornatos. [...] En medio de la bóveda hay una pintura á fresco de la Venida de nuestra Señora del Pilar, y es obra de D. Luis Velázquez. El Altar Mayor, que se vé adornado de quatro columnas de [p. 118] orden corintio, tiene en medio un baxo relieve de nuestra Señora del Pilar, que executó en estuco D. Joseph Ramírez, Escultor de Zaragoza. Encima de este Altar se representa el Espíritu Santo entre resplandores. La idea de este Altar es del D. Alexandro Velázquez (I). ${ }^{46}$

43 En 1729 es Refitolera, esto es, encargada del refectorio, y Sub-vicaria; en 1732, Ropera, Secretaria y Vicaria de Coro; conserva este último cargo en 1735, sumado al de Enfermera; pasa en 1738 a ser Portera de Torno y de nuevo Refitolera; en 1741 vuelve a ser Vicaria de Coro, cargo que conserva en 1744; en 1747 es Sacristana y Provisora.

44 En 1750 es Ropera y Refitolera; en 1753 es Sacristana y Refitolera; Vicaria de Coro en 1756; en 1759 Portera y Vicaria de Coro y Sacristía; Maestra de Novicias y Secretaria en 1762; en 1765 es aún Maestra de Novicias y Portera; en 1771 es Diputada, Tornera y Portera.

45 ARAMBURU DE LA CRUZ, 1766: 159.

46 PONZ, 1774, tomo III: 116-118. 
En la nota (I) Ponz traza una semblanza biográfica de los hermanos González Velázquez y de algunas de sus obras. Después, en cuerpo de texto (en p. 119) habla de los demás altares, ejecutados por D. Joseph Martín -el turolense José Martín de Aldehuela- bajo diseños de Ventura Rodríguez. Lo que, en cualquier caso, extraemos de estas informaciones es que, de un lado, Nebra había obtenido una reliquia de la Columna (el Pilar) de Zaragoza que cedió al convento conquense que por razones familiares le era próximo, y que favoreció económicamente a este convento hasta el punto de contribuir en gran medida a costear las obras de renovación de su iglesia, empresa en la que tuvo la colaboración de un canónigo de la catedral de Cuenca, al que Ponz llama "Diego Emo" y que debe identificarse con Diego Lujando, con el cual los Nebra tenían trato regular, como se deduce de algunos documentos ${ }^{47}$ En 1769 Lujando promovería la construcción de la Capilla del Pilar de la catedral de Cuenca, en la que intervino José Martín de Aldehuela.$^{48}$ No disponemos de datos exactos sobre el comienzo y remate de las obras de las Petras, pero, dado que sabemos que José Martín de Aldehuela colaboró en la nueva fábrica y en los retablos de esta iglesia en 1761, según trazas de Ventura Rodríguez y Alejandro González Velázquez, ${ }^{49}$ podemos deducir que los trabajos se verificaron simultáneamente a la construcción y decoración de la Santa Capilla del Pilar de Zaragoza, ${ }^{50}$ y además los diseños y, al menos en parte, la realización, estuvieron en manos del mismo equipo: Ventura Rodríguez -que también diseñó por esos años el Transparente de la catedral de Cuenca-, los hermanos González Velázquez y José Ramírez. Es decir, Nebra promovió la edificación y decoración de una suerte de réplica de la Santa Capilla del Pilar en el convento donde residía su sobrina, ${ }^{51}$ obra que sólo parcialmente podemos apreciar hoy, dado que, aunque la fábrica subsiste, el arte mueble y pinturas murales desaparecieron casi por completo durante la guerra civil.

Los mismos artistas -Rodríguez, Ramírez y los González Velázquez- venían colaborando en diversas obras de la fábrica y decoración del Palacio Real de Madrid, entre ellas, las de la Real Capilla. Nebra debió de tratar a Ventura Rodríguez, diseñador y responsable de la construcción de la nueva Capilla Real de Palacio, cuyas obras se dilataron entre 1749 y 1759. Es más que posible que Nebra diera sus opiniones sobre la ubicación de la tribuna para el órgano -que no llegaría a conocer, pues el instrumento de Jorge Bosch no fue entregado hasta 1778- y la capilla de música. No es descabellado pensar que en ese contexto también pudo trabar conocimiento con José Ramírez -con quien le unía su origen aragonés- y los González Velázquez. Tal vez por estos artistas, y sin duda a través de su hermano Joaquín, pudo estar al tanto de los trabajos en la Santa Capilla del Pilar de Zaragoza. Aunque no se ha estudiado suficientemente el grado de relación cotidiana, incluso de posible familiaridad, entre los músicos de la capilla y la cámara

47 Carta de José de Nebra al Deán de la catedral de Cuenca, Archivo de la catedral de Cuenca, Sección Secretaría, Cartas, 1749, cit. en ÁLVAREZ MARTÍNEZ, 1993: 197 (citado como "Luyardo"). Este canónigo Lujando figura en las respuestas al Catastro de Ensenada de 1752 como ganadero de reses bravas. Cfr. VICENTE LEGAZPI, 1996: 961-962.

48 Cfr. BARRIO MOYA, 1987.

49 BARRIO MOYA, 1991: 599-605, y CAMACHO MARTÍNEZ y SÁNCHEZ LÓPEZ, 2009-2010: 157-158.

$50 \mathrm{Y}$ en todo caso se hallaban finalizados en 1766, cuando Aramburu publicó su relación de las fiestas zaragozanas de 1765.

51 Parece claro, en todo caso, que existía con anterioridad en esa iglesia un altar dedicado a la Virgen del Pilar, a cuyos pies se hicieron enterrar los padres de Nebra. Sin embargo, posiblemente este altar no se encontraba en la cabecera de la iglesia, lugar que pasó a ocupar tras la reforma. 
y otros artistas -arquitectos, pintores, escultores...- $-^{52}$, con este cúmulo de coincidencias no resulta difícil atar cabos, o al menos formular suposiciones verosímiles.

También es lícito poner en conexión, siquiera hipotéticamente, esta maraña de obras que hunden sus raíces en Aragón -porque ya desde tiempo atrás el fenómeno pilarista se consideraba un símbolo aragonés- y de relaciones personales y profesionales con el peso que durante el siglo XVIII llegan a adquirir en la corte algunos personajes de procedencia aragonesa, que en determinados momentos parecen funcionar a modo de lobby. A lo largo de más de un siglo, la tribuna organística de la Real Capilla sólo se ve libre de músicos aragoneses durante poco más de siete años, los que van desde la muerte de Diego Jaraba y Bruna en 1716 a la contratación de José de Nebra en 1724: casi sin solución de continuidad se suceden Jaraba -desde 1677-, Nebra, José Moreno y Polo -hasta su muerte en 1774; éste, por cierto, era nacido en Hoz de la Vieja, localidad natal de José de Nebra padre- y Juan Sesé -hasta su muerte en 1801-. Lo relacionado con la estampación, encuadernación y cuidado de los libros en la corte también recae en manos aragonesas durante años, desde la presencia de Blas Nasarre como Bibliotecario Real hasta la actividad de las oficinas tipográficas de Antonio Sanz, Antonio Marín y Joaquín Ibarra. En materia de pintura, el último tercio del siglo está dominado por los zaragozanos Bayeu -a quienes Nebra quizá pudo tratar en sus últimos años-y, al fin, por Goya. Descendientes de los pintores zaragozanos Lorieri se establecen en Madrid a mediados de siglo para hacer carrera militar y política... Y en esta última actividad, ya desde fiales del reinado de Fernando VI, pero sobre todo en los primeros años del de Carlos III, se fragua lo que, usando el término acuñado por William Coxe, ha dado en llamarse "partido aragonés", representado por personalidades tan poderosas como el Conde de Aranda, Manuel de Roda, el Conde de Ricla, los Pignatelli...

En este hervidero artístico y político, José de Nebra, con sus particulares devociones y no sin importantes desembolsos, realiza -quién sabe si ignorando su trascendencia- una apreciable contribución a la construcción histórica de uno de los más conspicuos símbolos hispánicos.

\section{BIBLIOGRAFÍA}

AGUILAR PIÑAL, Francisco, Bibliografía de autores españoles del siglo XVIII, Tomo X, Anónimos II, Madrid, CSIC, 2002

ÁLVAREZ MARTÍNEZ, Ma. Salud, José de Nebra Blasco. Vida y obra, Zaragoza, Institución «Fernando el Católico», 1993

ANSÓN NAVARRO, Arturo, "La Santa Capilla del Pilar, centro de formación artística en el siglo XVIII", en FATÁS CABEZA, Guillermo (coord..), El Pilar desconocido, Zaragoza, Heraldo de Aragón, 2006, pp. 129-132

ANSÓN NAVARRO, Arturo y BOLOQUI LARRAYA, Belén, "Zaragoza Barroca”, en FATÁS CABEZA, Guillermo (coord.), Guía histórico-artística de Zaragoza, Zaragoza, Ayuntamiento (Servicio de acción cultural), $1991^{3}$, pp. 249-327

52 Para fechas más tempranas puede consultarse MORALES, 2007. 
ARAMBURU DE LA CRUZ, Manuel Vicente, Historia Chronológica de la Santa, Angélica, y Apostólica Capilla de Nuestra Señora del Pilar de la Ciudad de Zaragoza [. . .], Zaragoza, Imprenta del Rey, 1766 ARELLANO, Ignacio y EICHMANN, Andrés (eds.), Entremeses, loas y coloquios de Potosí (Colección del convento de Santa Teresa), Madrid, Archivo y Biblioteca Nacionales de Bolivia y Centro de Estudios Bolivianos Avanzados, 2005.

ARMILLAS VICENTE, José Antonio, DOMINGO PÉREZ, Tomás, SAN VICENTE PINO, Ángel y TORRA DE ARANA, Eduardo (eds.), El Pilar de Zaragoza, Zaragoza, Caja de Ahorros de la Inmaculada, 1984

BARAUT, Dom Cipriano, García Jiménez de Cisneros. Obras completas, I. Introducción en índices [Scripta et documenta 15], Abadía de Montserrat, 1965

BARRIO MOYA, José Luis, “José Martín de Aldehuela en Cuencala capilla del Pilar en la catedral”, en Boletín del Museo e Instituto Camón Aznar, 29, 1987: 123-130

-, Arquitectura barroca en Cuenca, Madrid, Universidad Complutense, 1991

BLANCO MOZO, Juan Luis, “Juan Sánchez Barba (1602-1673), escultor”, en Anuario del Departamento de Historia y Teoría del Arte (UAM), 17, 2005: 115-130.

BUENDÍA MUÑOZ, José Rogelio, La Ermita de San Antonio de la Florida: historia e itinerario artístico, Madrid, Ayuntamiento de Madrid, 1992

BUESA CONDE, DOMINGO J. (ed.), El Pilar es la Columna. Historia de una devoción, Zaragoza, Gobierno de Aragón y Ayuntamiento de Zaragoza, 1995

CAMACHO MARTÍNEZ, Rosario y SÁNCHEZ LÓPEZ, Juan Antonio, “¿De forma defectuosa y gusto depravado? un proyecto inédito de José Martín de Aldehuela para el tabernáculo de la Catedral de Málaga (1796)", en Boletín de Arte [del Departamento de Arte, Universidad de Málaga], 30-31, 2009-2010: 147-168

COTARELO Y MORI, Emilio, Bibliografía de las controversias sobre la licitud del teatro en España, Madrid, Establecimiento Tipográfico de la Revista de Archivos, Bibliotecas y Museos, 1904

DELCLAUX, Federico y SANABRIA, José María, Guía para visitar los santuarios marianos de Madrid, Madrid, Ediciones Encuentro, 1991

DOMINGO PÉREZ, Tomás, ANSÓN NAVARRO, Arturo y RUIZ PARDO, Juan, La cúpula de González Velázquez sobre la Santa Capilla del Pilar, Zaragoza, Gobierno de Aragón, 1998

EBAS, Juan de las, Historia breve de la portentosa imagen de Nuestra Señora del Milagro [...], Madrid, 1712 ESTEBAN LORENTE, Juan Francisco, "Ventura Rodríguez al servicio de una idea. La Santa Capilla de la Virgen del Pilar de Zaragoza”, en Artigrama, 4, 1987: 157-206

—, "Significado de las proporciones del templo del Pilar y de la Santa Capilla", en FATÁS CABEZA, Guillermo (coord..), El Pilar desconocido, Zaragoza, Heraldo de Aragón, 2006, pp. 133-137

EZQUERRO ESTEBAN, Antonio, "Nuevos datos para el estudio de los músicos Nebra en Aragón”, en Anuario Musical, 57, 2002: 113-156

—, "José de Nebra entre España y la Nueva España: fuentes documentales de música -dimensión internacional- para su estudio", en Lope de Barrientos. Seminario de Cultura, 3, 2010 [2011]: 59-104 
FERNÁNDEZ GARCÍA, Matías, Parroquia madrileña de San Sebastián. Algunos personajes de su archivo. Madrid, Caparrós, 1995

FINNEGAN, Mary Jeremy, The Women of Helfta: Scholars and Mystics (Second revised edition), Athens, University of Georgia Press, 1991

GONZÁLEZ MARÍN, Luis Antonio, José de Nebra: Oficio y Misa para las Reales Honras de la Reina $D^{a}$. María Bárbara, que goza de Dios, Madrid, ICCMU, 2003

- , "José de Nebra y los autos sacramentales", en BORREGO, Esther y GONZÁLEZ MARÍN, Luis Antonio (eds.), La divina Filotea, auto sacramental de Pedro Calderón de la Barca (1600-1681), música de José de Nebra (1702-1768), Madrid, Fundación Caja Madrid, 2008: 16-19

_, "Una reflexión sobre la música de tecla de José de Nebra”, en Delantera de paraíso. Estudios en homenaje a Luis G. Iberni, Madrid, ICCMU, 2008: 591-612

—, José de Nebra: Miserere a dúo. Miserere a ocho, Madrid, ICCMU, 2010

—, El Himno de Santa Isabel, Reina de Portugal, de José de Nebra, 1758, Zaragoza, Diputación Provincial de Zaragoza, 2011

KLEINERTZ, Rainer, Grundzüge des spanischen Musiktheaters im 18. Jahrhundert. Ópera, comedia, zarzuela (2 vols.), Kassel, Reichenberger, 2003

MORALES, Nicolas, L'artiste de cour dans l'Espagne du XVIII e siècle. Étude de la communauté des musiciens au service de Philippe V (1700-1746), Madrid, Casa de Velázquez, 2007

PÉREZ PASTOR, Cristóbal, Noticias y documentos relativos a la historia y literatura españolas, Tomo I [Memorias de la Real Academia Española, Tomo X], Madrid, Hijos de Reus [Imprenta de la Revista de Legislación], 1910

PERIS LACASA José et al., Catálogo del archivo de música del Palacio Real de Madrid, Madrid, Patrimonio Nacional, 1993

PONZ, Antonio, Viage de España [...] Tomo tercero, Madrid, Joaquín Ibarra, 1774

RINCÓN GARCÍA, Wifredo, El Pilar de Zaragoza, Zaragoza, Everest, 2000, pp. 19-26

SALDONI, Baltasar, Diccionario biográfico-bibliográfico de efemérides de músicos españoles, Madrid, Imprenta de D. Antonio Pérez Dubrull, 1868-1881

SANDOVAL DÍEZ, Eva María, Los responsorios de Navidad de José de Nebra (1702-1768): Reformas en la Capilla Real de Madrid a mediados del siglo XVIII (Trabajo de Investigación de Tercer Ciclo, inédito), Madrid, Universidad Complutense, 2011

USÓN GARCÍA, Ricardo, La intervención de Ventura Rodríguez en el Pilar: la Santa Capilla generatriz de un sueño arquitectónico, Zaragoza, Delegación del Colegio Oficial de Arquitectos de Aragón, 1990

VICENTE LEGAZPI, María Luz N., La ganadería en la provincia de Cuenca en el siglo XVIII, Cuenca, Universidad de Castilla La Mancha, 1996

Recibido: $12 / 03 / 2012$

Aceptado: 21/02/2013 